the physical world as they have been revealed to us in the twentieth century. We know now that the childish mechanical conceptions of the nineteenth century are grotesquely inadequate. We have now no one consistent scheme of interpretation of physical phenomena and we have become wise enough to see and to admit that we have none. We hare learned to work with new enthusiasm and new hope and new joy, because there is still so much that we do not understand; because we have actually succeeded in our lifetimes in finding more new relations in physics than had come to light in all preceding ages put together; and because the stream of discovery as yet, shows no sign of abatement."

\title{
A Modified Form of the True-False Test
}

\section{By Howard Y. MoClusky and Fraxcis D. Curtis, University of Michigan.}

Ever since its first appearance, about seven years ago, the True-False test has been a widely-used and popular measuring device. Recently, moreover, its popularity seems to be increasing with the teachers of science, particularly of general science, a fact which is indieated by the recent appearance of sereral standardized True-False tests in that subject.

While the True-False is doubtless a useful and valuable form of test, there has always been considerable objection to it beause (1) it facilitates the "proclivity to borrow from one's neighbor," (2) it is unsatisfactory "as an instrument for diagnosing special individual difficulties,"2 and (3) it permits more or less successful guessing of the correct response. Is regards this third criticism, while Ruch states that "pure guessing (in the True-False) is comparatively rare with most individuals,"3 some guessing, nevertheless, is generally admitted as a probability, and consequently the "guessing factor" constitutes probably the most serious objection to the True-False; for one cannot tell whether the correct response to any given

1 F. B. Knight, "Data on the True-False Test as a Device for College Fxaminations," Journal of Educational Psychology, XIII (1922), 75-80.

2 H. M. Barthelmess, "Reply to a Criticism of Tests Requiring Alterna.tive Response," Journal of Educational Research, VI (1922), 357-59.

3 Giles M. Ruch, "The Improvement of the Written Examination," (New York: Scott, Foresman \& Co., 1925) pp. 116-17. 
True-False statement is the result of accurate knowledge or elever analysis, or of lucky guessing.

The authors have recently completed a limited investigation with a modified form of the True-False, which seems in so far as the results may be indicative, to possess several marked advantages over the original form. The investigation was conducted with five calsses in science in the University (of Michigan) High School, one each in ninth and seventh-grade general science, two in eighth-grade general science, and one in tenthgrade biology. $\Lambda$ test of fifty true-false items was prepared for each class; each test was divided into two halves, each half containing the same number of true statements, but having about twice as many false as true statements. The items in the respective halves were paired as accurately as could be done subjestively with respect to type and difficulty. For each class the entire set of statements was mimeographed as Sheet I, and an ex:ct duplicate of the items on Sheet I was mimeographed as Sheet II, with the exception that the items in the second half of I became those of the first half of II. Thus numbers one to twenty-five on Sheet I became numbers twenty-six to fifty on Sheet II, and vice versa. Both Sheets I and II were administered to each class during a single class period.

The directions upon Sheet I were as follows:

Some of the following statements are true, and some are false. Put a letter " $T$ " in the left margin opposite the statements you consider to be true as stated, and an "F" opposite those you consider false. Do not fail to mark all of the statements. In all cases when in doubt guess.

Examples: 1. T Carbon dioxide is more dense than air.

2. F Carbon dioxide is more dense than water.

The directions upon Sheet II were as follows:

Some of the following statements are true and some are false. Put a letter "T" in the left margin opposite the statements you consider to be true as stated, and correct the statements you consider to be false, by changing not more than two words in the original statement so as to make it true. Make all changes in the form of substitutions. No credit will be given for false statements which are corrected merely by the insertion of the word "Not." Do not change the subjects of any of the statements.

Examples: 1. T Carbon dioxide is more dense than air. less

2. Carbon dioxide is more dense than water. 
SOME TYPICAL ITEMS AND RESPONSES, SELECTED FROM THI VARIOUs SheETs I, Follow :

1. T An eclipse of the moon occurs only at full moon.

2. F An inflated tire weighs less than it would if it were not inflated.

3. F The plant seed contains the embryo and all the substances needed for its development except fat.

4. F The response which plants make to gravitation is called phototropism.

5. F A fireplace heats the room mostly by conduction.

Correct responses to these same items on the corresponding Sheets II follow:

1. T An Eclipse of the moon occurs only at full moon. more

2. An inflated tire weighs less than it would if it were not inflated.

(If allowed to change three words, the pupil may correct this item thus:)

A deflated

2. An inflated tire weighs less than it would if it were not deflated inflated.

3. The plant seed contains the embryo and all the sul)water stances needed for its development except fat.

light

4. The response which plants make to gravitation is called photopism. (Or, since this item can be made correct by substitutions in two different ways:)

4. The response which plants make to gravitation is called geotropism phototropism. radiation

5. A fireplace heats the room mostly by conduction.

It will be noted that the sqle difference in the two test sheets is that with Sheet $I$, the pupil is required only to decide whether the statements are true or false, and then to mark them $\mathrm{T}$ or $\mathrm{F}$, as the case may be; but with Sheet II, he must not only decide whether the same statements are true or false, but he must analyze the false ones to detect what the false element or elements in them are, and then must substitute for the falso words others which correct the inaccuracies in the original statements. 
The INVESTIGATION FURNished EVIDENCE IN SUPPORT OF THE FOLLOWING CONCLUSIONS:4

1. The Modified Form takes more time to administer than the True-False. For the five classes in science, the average difference in median time was 38.2 per cent. In marking the tests, it was found, moreover, that somewhat more time is required to score the Modified Form than the True-False, though, after a few papers have been scored, the extra time required for the Modified Form is very little. With respect to statements which admit of more than one correct answer, it is easily practicable to make a key which indicates the acceptable alternatives.

Occasionally, as in the Completion Form of test, though less frequently in this Modified Form of True-False, an admissible answer is given which did not occur to the examiner in making the test; but these cases are relatively rare, and their noting does not require much additional time, nor do such sporadic cases appreciably affect the objectivity of the test.

It should be stated, also, that in so far as could be judged, it takes not longer to construct items for the Modified Form than it does to make good statements for the conventional True-False; and from the nature of the corrections required, the Modified Form is probably apt to contain fewer inconsequential items than the True-False. One, moreover, soon acquires the knack of constructing suitable test items for the Modified Form.

It may appear, on first thought, that the pupils themselves will not be able to score the Modified Form, but practice shows that they can score it satisfactorily. Slightly more time is required in scoring the Modified Form than is needed by them in correcting the True-False, but this added expenditure of time is amply justified through the added discussion occasioned by the effort to determine the proper answers. Further discussion gives the Modified Form a teaching value superior to that of the True-False.

2. The Modified Form possesses a greater usefulness in homogeneous Grouping for drill upon certain units of work than does the True-False. This fact is indicated by the consistently greater standard deviations of the Modified Form. The Modified Form, moreover, is superior to the True-False

4 For the statistical evidence supporting these various numbered statements, see the authors' complete report of this investigation in the Journal of Educational Research, XII (1926), 213-24. 
for the diagnosis of individual and class difficulties and weaknesses. For example, oceasionally a pupil changes a statement which is already correct in such a way that it is still correct, though with altered meaning; such a reaction is therefore welcomed as being indicative of confusion about that particular point in the pupil's mind, and as revealing a teaching opportunity which the True-False could not bring to light.

3. The Modified Form is a better power test than the TrueFalse. A number of the more able pupils actually scored several points higher in the Modified Form than in the Old Form, because, as several stated, under the necessity for more careful analysis and reasoning in the former, they discovered meanings overlooked when taking the True-False. On the other hand, the weaker pupils, almost without exception, made higher scores in the True-False.

4. The Modified Form is more reliable than the True-False. The reliability of the former, computed from Brown's formula, was found to be .9:, and of the latter, .82. The reliability of the Modified Form, moreover, compares favorably for tests in science with the reliability of the Recall and Multiple Response tests experimented upon by Ruch. ${ }^{5}$ The reliability of Ruch's Recall and Five-Response tests, computed also from Brown's formula, were respectively .90 and .89 .

5. The Modified Form is more difficult for the pupils than the True-False. The stronger pupils, however, like the Modified Form better. They enjoy the challenge of the puzzle element and the stimulus to wholesome competition offered by the Modified Form, which they think gives them a better chance to reveal what they really know. This Modified Form, moreoyer, since it demands a focus of attention upon content, eliminates whatever tendency there may be on the part of the more alert pupils to concentrate upon the mere mechanics and technique of wording of the statements.

6. The Modified Form tends to eliminate whatever elements of guessing may be functioning in the True-False. Lucky guessing seems hardly possible in a statement demanding the changing of one or two words. With the Modified Form, moreover, the "guessing factor" can be entirely eliminated by making all the statements false, and by so informing the pupils at the beginning of the test.

5 Ruch, op. cit. p. 99. 